\title{
Home-based vaccination records and hypothetical cost- savings due to avoidance of re-vaccinating children
}

\author{
David W Brown ${ }^{1, *}$ \\ ${ }^{1}$ United Nations Children's Fund (UNICEF), Three UN Plaza, New York, USA
}

As national immunization programmes, particularly those in low- and middle-income countries where administrative recording of services received is often absent or suboptimal, enter a period of rapidly paced change with new vaccine introductions, it seems important to identify ways to avoid unnecessary re-vaccination of children and the associated costs. Some re-vaccination may be unavoidable, while other re-vaccination is almost certainly avoidable but nevertheless occurs. Unfortunately, the prevalence and epidemiology of re-vaccination of children are illdescribed, and potential risks due to re-vaccination are either nil or also unknown. Nonetheless, it is seemingly important to better understand avoidable re-vaccinations that occur as a result of a breakdown along the service delivery continuum.

The role of the home-based vaccination record as a critical health record for documenting vaccinations received by children and as a point-of-care information resource to enhance health professionals' ability to make clinical decisions and prevent unnecessary repetition of vaccination has been described $[1,2]$. Unfortunately, vaccination cards are not always viewed as a critical component of the vaccination service delivery bundle, and as a result they are far too often not printed and/ or distributed, underutilized or inappropriately used by parents and health care workers and therefore do not always fulfil their intended purpose [1]. Low prevalence of home-based vaccination records observed in nationally representative, population-based household surveys [3], such as the Demographic and Health Surveys or the Multiple Indicator Cluster Surveys, is a signal of a larger illunderstood problem affecting many countries. Moreover, short-run costs of printing childhood vaccination cards are often cited as an underlying reason for sub-optimal card stock availability. Unfortunately, this short-run perspective may overlook potential cost savings achievable due to avoidance of re-vaccination in the presence of high card availability and cardholder prevalence.
With this in mind, we computed a crude estimate of the potential cost savings due to avoidance of re-vaccinating children as a result of ensuring high prevalence of homebased vaccination records. To do so, we considered a hypothetical cohort of 100,000 children. In the base scenario we assumed that all children survive to their first birthday (i.e., no infant mortality); $100 \%$ card availability, compliance and retention, a cost per card of US $\$ 1$, and a cost for a fully vaccinated child of US\$50 per child. In the early days of the Expanded Programme on Immunization [4], a fully immunized (or perhaps more appropriately 'vaccinated') child was most often defined (at least operationally) as a child who received Bacille CalmetteGuérin (BCG) vaccine, three doses of diphtheria-tetanuspertussis (DTP) containing vaccine, three doses of polio vaccine and one dose of measles containing vaccine per the national immunization schedule in a given country. As new vaccines have been added to this basic package, the definition of the fully vaccinated child has correspondingly changed by country, and continues to change. As one might expect with overall costs of immunizing children increasing [5] and changes in type of vaccine technology and delivery strategy utilized, the scale of operation, and country-specific and environmental characteristics [6], the cost per fully vaccinated child is also in flux.

We then examined the potential costs savings by varying the proportion of children re-vaccinated under scenarios

\footnotetext{
*Corresponding author: David W Brown, United Nations Children's Fund (UNICEF), Three UN Plaza, New York, USA. Tel.: +1 212303 79 88; Email: dbrown@unicef.org
}

Received 10 March 2014 Revised 15 April 2014 Accepted 22 April 2014 Published 29 April 2014

Citation: Brown DW (2014) Home-based vaccination records and hypothetical cost-savings due to avoidance of re-vaccinating children. J Vaccines Immun 2:1-3. doi:10.14312/2053-1273.2014-e1

Copyright: (C) 2014 Brown DW, et al. This is an open-access article distributed under the terms of the Creative Commons Attribution License, which permits unrestricted use, distribution and reproduction in any medium, provided the original author and source are credited. 
where the cost of re-vaccination is $25 \%, 50 \%, 75 \%$ and $100 \%$ of the cost for a fully vaccinated child. The latter was completed under the notion that the number of vaccines, and thereby the costs, for which a child is re-vaccinated will vary, with a low probability that many children would be re-vaccinated with the complete vaccine series (i.e., cost of re-vaccination is essentially a doubling of the cost). The exercise was repeated varying the cost per fully vaccinated child (US\$30, US\$40). These estimates were based on reported immunization expenditures per infant (not cost per fully vaccinated child, for which we were unable to find recent information) ranging from US $\$ 14$ in Southeast Asia to US\$41 in Europe [7] and costs per infant vaccinated with three doses of DTP ranging from US $\$ 28$ to US $\$ 48$ (2009 US\$) [5].
In the base scenario, the cost of vaccinating 100,000 infants assuming 1) no re-vaccination, 2) US $\$ 50$ per fully vaccinated child (FVC) and 3 ) a cost per card of US $\$ 1$, the potential annual cost savings if a programme avoided re-vaccinating $20 \%$ of the birth cohort was $\$ 750,000$ at $75 \% \mathrm{FVC}$ cost and $\$ 500,000$ at $50 \% \mathrm{FVC}$ cost (Figure and Table). The potential annual cost savings increased to US $\$ 2,500,000$ at $100 \%$ FVC cost if the programme avoided re-vaccinating $50 \%$ of the cohort. As expected, increasing the cost per fully vaccinated child from US $\$ 30$ to US $\$ 50$ or increasing the proportion of re-vaccinations avoided (ceteris paribus) leads to greater potential cost savings (Table).

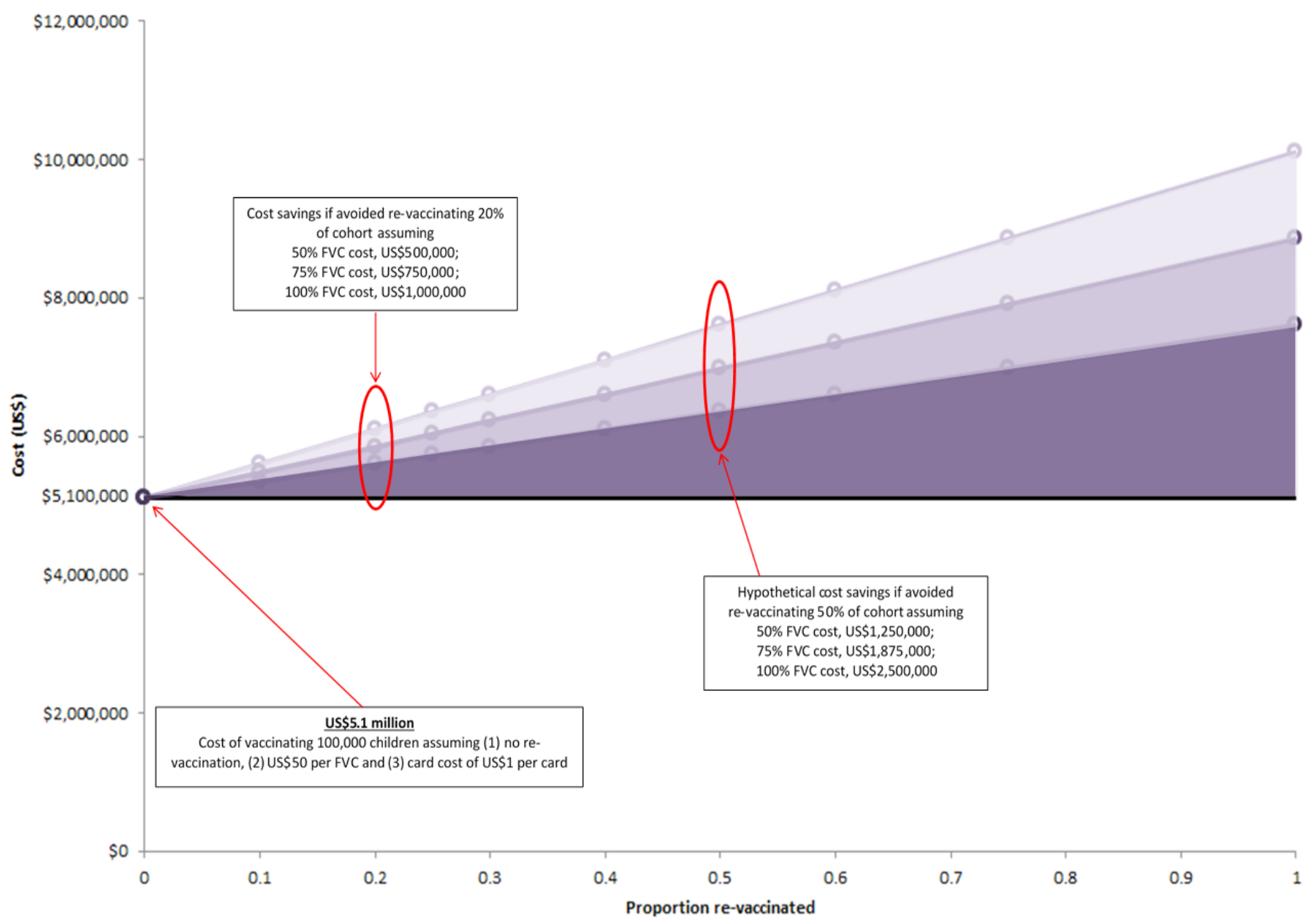

Figure Shaded area represents potential cost-savings due to avoidance of re-vaccinating children assuming $100 \%$ vaccination card compliance by proportion re-vaccinations avoided and where re-vaccination cost is $50 \%, 75 \%$ and $100 \%$ of the cost for a fully vaccinated child (US\$50 per FVC) in a hypothetical birth cohort of 100,000 children.

This exercise, albeit an oversimplification of reality, further highlights an economic argument for increased attention towards home-based vaccination records for documenting childhood (particularly for infants) vaccinations received. Given that a child could be revaccinated an infinite number of times in the complete absence of appropriate documentation, these estimates may underestimate the potential savings. In the short- run, home-based vaccination records offer an inexpensive and easily implemented option, particularly in lowresource settings and during a period of scarce resources where the potential cost savings achieved from the avoidance of re-vaccination is not to be overlooked. In the hypothetical example above, a cost savings of US $\$ 1$ million dollars is equivalent to the amount need for vaccinating an additional 20,000 infants at US $\$ 50$ per 
Table Potential cost savings due to avoidance of re-vaccinating children as a result of immunization cards assuming $100 \%$ card availability, utilization and compliance by proportion of re-vaccinations avoided and where re-vaccination cost is $25 \%, 50 \%, 75 \%$ and $100 \%$ of the cost for a fully vaccinated child in a hypothetical birth cohort of 100,000 children.

\begin{tabular}{|c|c|c|c|c|c|c|c|c|c|c|c|c|c|c|}
\hline \multirow{4}{*}{$\begin{array}{l}\text { Cost } \\
\text { /FVC } \\
\text { (US\$) }\end{array}$} & \multirow{4}{*}{$\begin{array}{c}\text { Card } \\
\text { cost } \\
\text { (cost/ } \\
\text { card, } \\
\text { US\$1) }\end{array}$} & \multirow{4}{*}{$\begin{array}{l}\text { Vaccination } \\
\text { cost (US\$) }\end{array}$} & \multicolumn{12}{|c|}{$\begin{array}{l}\text { Potential cost savings (US\$, x1000) } \\
\text { (i.e., avoided cost of re-vaccination) }\end{array}$} \\
\hline & & & \multicolumn{3}{|c|}{$25 \%$ of $F V C$} & \multicolumn{3}{|c|}{$50 \%$ of $F V C$} & \multicolumn{3}{|c|}{$75 \%$ of $F V C$} & \multicolumn{3}{|c|}{$\begin{array}{c}100 \% \text { of FVC } \\
\text { (i.e., re-vaccinating } \\
\text { with all antigens) }\end{array}$} \\
\hline & & & \multicolumn{3}{|c|}{$\begin{array}{l}\text { Proportion re-vaccinations } \\
\text { avoided }\end{array}$} & \multicolumn{3}{|c|}{$\begin{array}{l}\text { Proportion re-vaccinations } \\
\text { avoided }\end{array}$} & \multicolumn{3}{|c|}{$\begin{array}{c}\text { Proportion re-vaccinations } \\
\text { avoided }\end{array}$} & \multicolumn{3}{|c|}{$\begin{array}{l}\text { Proportion re-vaccinations } \\
\text { avoided }\end{array}$} \\
\hline & & & 0.10 & 0.25 & 0.50 & 0.10 & 0.25 & 0.50 & 0.10 & 0.25 & 0.50 & 0.10 & 0.25 & 0.50 \\
\hline 30 & 100,000 & $3,000,000$ & 75 & 187.5 & 375 & 150 & 375 & 750 & 225 & 562.5 & 1125 & 300 & 750 & 1500 \\
\hline 40 & 100,000 & $4,000,000$ & 100 & 250 & 500 & 200 & 500 & 1000 & 300 & 750 & 1500 & 400 & 1000 & 2000 \\
\hline 50 & 100,000 & $5,000,000$ & 125 & 312.5 & 625 & 250 & 625 & 1250 & 375 & 937.5 & 1875 & 500 & 1250 & 2500 \\
\hline
\end{tabular}

Abbreviations: FVC: fully vaccinated child

FVC, 25,000 infants at US $\$ 40$ per FVC or more than 30,000 infants at US\$30 per FVC in our hypothetical cohort of 100,000 infants. Of course, assurance of an adequate supply and distribution of home-based vaccination records by national immunization programmes must be complemented by equally important efforts to ensure that the records are appropriately and legibly completed by health professionals at the time of service, transferred to caregivers with appropriate education on the importance of retaining the record and keeping it safe from damage, and then retained and referenced by the caregivers.

The addition of new, more expensive (at least in the short-run) vaccines may serve as an impetus for national immunization programmes, international nongovernmental organizations, and others providing funding and technical support to refocus on the importance of home-based vaccination records as a primary component of the vaccine service delivery bundle with the aim to improve communication and coordination in delivering high quality, patient-centred care while decreasing unnecessary and costly re-vaccinations. Further efforts are also needed to prevent stock-outs of home-based vaccination records that in some countries have lasted six months to one-year and longer. And, efforts to examine the viability of electronic health records [8] in the long run, including those that would enable recording vaccinations received across the lifespan and incorporate reminders for caregivers/patients of upcoming vaccinations, may be particularly important. Finally, further research is needed to better understand why some caregivers retain home-based vaccination records while others do not in order to inform potential programme changes, including improved communication and introduction of incentive structures.

\section{Disclaimer}

The views and opinions expressed here are those of the author alone and do not necessarily reflect those of their respective institution.

\section{Acknowledgement}

The author would like to thank Mr. Gian Gandhi for his thoughtful comments on previous versions of this manuscript.

\section{Conflict of interest}

The authors wish to express that they have no conflict of interest.

\section{References}

[1] Brown DW (2012) Child immunization cards: essential yet underutilized in national immunization programmes. Open Vaccine J 5:1-7.

[2] Brown DW, Gacic-Dobo M, Young SL (2014) Home-based child vaccination records--a reflection on form. Vaccine 32:1775-1777.

[3] Home-based vaccinationcard prevalence. (Website accessed 24 April 2014). https://sites.google.com/site/vaccinationcardprevalence/.

[4] Bland J, Clements J (1998) Protecting the world's children: the story of WHO's immunization programme. World Health Forum 19:162-173.

[5] Brenzel L, Politi C (2012) Historical Analysis of the Comprehensive Multi-Year Plans in GAVI-Eligible countries (2004-2015). http:// www.who.int/immunization/programmes_systems/financing/ analyses/Historical_cMYP_Analysis_2012.pdf.

[6] Brenzel L, Claquin P (1994) Immunization programs and their costs. Soc Sci Med 39:527-536.

[7] Kamara L, Lydon P, Bilous J, Vandelaer J, Eggers R, et al. (2013) Global Immunization Vision and Strategy (GIVS): a mid-term analysis of progress in 50 countries. Health Policy Plan 28:11-19.

[8] Kamadjeu RM, Tapang EM, Moluh RN (2005) Designing and implementing an electronic health record system in primary care practice in sub-Saharan Africa: a case study from Cameroon. Inform Prim Care 13:179-186. 